\title{
Determination of diffusion in polycrystalline platinum thin films
}

\author{
Michael DiBattista and Johannes W. Schwank ${ }^{\text {a) }}$ \\ Department of Chemical Engineering, University of Michigan Ann Arbor, Michigan 48109-2136
}

(Received 28 April 1999; accepted for publication 26 July 1999)

\begin{abstract}
Grain boundary diffusion of titanium through platinum thin films has been carried out in the temperature range from 200 to $600{ }^{\circ} \mathrm{C}$. Five different platinum/titanium bilayer thicknesses, from 35 to $800 \AA \mathrm{Pt}$, were annealed in $5 \% \mathrm{O}_{2} / 95 \% \mathrm{~N}_{2}$. The accumulation of titanium at the platinum surface layer was measured by x-ray photoelectron spectroscopy (XPS) to determine the grain boundary diffusion coefficient $\left(D_{b}\right)$. Diffusivity values were calculated based on two different analysis methods assuming type $C$ kinetics. For Pt layers thicker than $200 \AA$, the activation energy $\left(Q_{b}\right)$ for titanium diffusion was found to be $118 \pm 15 \mathrm{~kJ} / \mathrm{mol}(1.22 \pm 0.16 \mathrm{eV})$. For Pt layers thinner than 200 $\AA$, there was a thickness dependence on the diffusion kinetics, resulting in activation energies as low as $20 \pm 4 \mathrm{~kJ} / \mathrm{mol}(0.21 \pm 0.04 \mathrm{eV})$. XPS results gave no evidence for any Pt-Ti alloy formation in these layers. The suppression of alloy formation may be attributed to the presence of oxygen at the $\mathrm{Pt} / \mathrm{Ti}$ interface during layer deposition. The quantitative analysis of titanium interdiffusion in platinum provides valuable information regarding Pt/Ti surface concentrations in thin-film chemical sensors, and for understanding changes in operational characteristics of platinum electrodes. (C) 1999 American Institute of Physics. [S0021-8979(99)04321-2]
\end{abstract}

\section{INTRODUCTION}

The solid state interdiffusion of titanium (Ti) in platinum $(\mathrm{Pt})$ is a well known phenomenon. ${ }^{1,2}$ These materials are used together in applications such as dynamic random access memory (DRAM) devices, ${ }^{3-6}$ thin film chemical sensors, ${ }^{7-10}$ and heterogeneous catalysts. ${ }^{11,12}$ Each of these applications use Pt and Ti layers of different thicknesses to meet different objectives.

At lower temperatures, the primary diffusion mechanism in polycrystalline thin films is migration through the grain boundaries. ${ }^{13}$ Titanium has been found to be the diffusing species in many bilayer metal film systems including $\mathrm{Pt} / \mathrm{Ti},{ }^{1,2,6} \mathrm{Ti} / \mathrm{Rh},{ }^{2} \mathrm{Ti} / \mathrm{Au},{ }^{1}$ and $\mathrm{Ti} / \mathrm{Pd},{ }^{1}$ primarily based on $\mathrm{Ru}-$ therford backscattering spectroscopy (RBS) results. The diffusion of the titanium atoms affect the operation of integrated circuits, the structure and operation of chemical sensing films, and the reactivity of catalysts. For the Pt/Ti system, diffusion data for the activation energy $\left(Q_{b}\right)$ and the diffusion pre-exponential factor $\left(D_{0}\right)$ are not available in solid state diffusion literature ${ }^{14-16}$ but the solid state diffusion of many metal bilayers is exponentially dependent on temperature as follows:

$$
D=D_{0} \exp \left(-Q_{b} / R T\right) .
$$

The background for solid state diffusion in thin films has been well established. ${ }^{13,15-17}$ There are several direct methods for determining diffusion rate in materials. Surface accumulation methods can be very effective at measuring diffusivity because they have the advantage of allowing the diffusing species to collect on the surface over time and then be quantified. The amount of Ti on the surface of the Pt layer can be measured with surface characterization techniques

\footnotetext{
a)Electronic mail: schwank@engin.umich.edu
}

such as Auger electron spectroscopy (AES), infrared spectroscopy (IR) ${ }^{18}$ or x-ray energy photoelectron spectroscopy (XPS) and indicates the rate of diffusion through the film. Several models that relate the surface concentration of a species to the diffusivity are available. ${ }^{15}$

The idealized diffusion case for type $C$ kinetics ${ }^{19}$ (grain boundary dominated) with a constant diffusion source and a diffusion barrier at the top surface has been solved by Holloway and McGuire. ${ }^{20}$ The analytical solution to this type of problem is analogous to conventional heat transfer problems such as conduction through a wall next to an infinite heat sink [Eq. (2)]

$$
C_{s}=C_{0}+\frac{4 C_{0}}{\pi} \sum_{n=0}^{\infty} \frac{(-1)^{n+1}}{2 n+1} \exp \left[-\frac{D_{b} t(2 n+1)^{2} \pi^{2}}{4 L^{2}}\right] .
$$

The concentration $\left(C_{s}\right)$ of $\mathrm{Ti}$ on the surface is a function of the initial concentration $\left(C_{0}\right)$, film thickness $(L)$, the annealing time $(t)$, and the grain boundary diffusion coefficient $\left(D_{b}\right)$. In addition, a solution for grain boundary diffusion in an array of parallel grain boundaries has been solved by Hwang and Balluffi ${ }^{21}$ [Eq. (3)] using the heat transfer solution by Carslaw and Jaeger ${ }^{22}$

$$
C_{s}=1-2 \sum_{n=1}^{\infty} \exp \left(-\theta_{n}^{2} t_{b}\right)\left[\frac{\left(\theta_{n}^{2}+H^{2}\right) \sin \theta_{n}}{\left(\theta_{n}^{2}+H^{2}+H\right) \theta_{n}}\right] .
$$

The relationship for the concentration of Ti on the surface of the Pt film after annealing is an infinite series that depends on a dimensionless time $\left(t_{b}\right)$, a dimensionless grain boundary to surface capacity ratio $(H)$, and $\theta_{n}$. The variable $\theta_{n}$ is the solution to the transcendental function $\theta_{n} \tan \theta_{n}=H$ for each term in the series. The dimensionless time is a function of the grain boundary diffusivity $\left(D_{b}\right)$, the annealing time $(t)$, and the thickness of the film $(L)$ [Eq. (4)]. 


$$
t_{b}=\frac{D_{b} t}{L^{2}} .
$$

The dimensionless time is solved for and then the grain boundary diffusion coefficient is determined. The grain boundary to surface capacity ratio, $H$, is shown as follows:

$$
H=\frac{\delta_{b} L}{s^{\prime} \delta_{s} d} \text {. }
$$

The dominant terms are the film thickness, $L$, and the grain size, $d$. The grain size for these films was determined by transmission electron microscopy, scanning electron microscopy (SEM), or x-ray diffraction. The grain boundary width $\left(\delta_{b}\right)$ and the surface accumulation height $\left(\delta_{s}\right)$ were set equal to each other, and the surface segregation factor $\left(s^{\prime}\right)$ was set equal to one. An Arrhenius plot of the grain boundary diffusion coefficient $\left(D_{b}\right)$ versus the inverse absolute temperature from several annealed films can be made to calculate the diffusion pre-exponential factor and activation energy for the diffusion of the titanium through the platinum. With a quantitative measurement for grain boundary diffusion in $\mathrm{Pt} / \mathrm{Ti}$ layers, the diffusion kinetics of the system can be predicted. The objective of this investigation is to quantitatively measure the activation energy and diffusion preexponential factor for grain boundary diffusion in the Pt/Ti system.

\section{EXPERIMENT}

Five different thicknesses of platinum and titanium films were deposited at room temperature by electron beam evaporation under ultrahigh vacuum conditions onto four-inch thermally oxidized (8000 $\AA$ ) silicon wafers. In between the titanium layer and the deposition of the platinum layer, the chamber was vented to the ambient environment. The film samples were $35 \AA \mathrm{Pt} / 65 \AA \mathrm{Ti}, 65 \AA \mathrm{Pt} / 130 \AA \mathrm{Ti}, 200 \AA$ $\mathrm{Pt} / 200 \AA \mathrm{Ti}, 500 \AA \mathrm{Pt} / 500 \AA \mathrm{Ti}$, and $800 \AA \mathrm{Pt} / 800 \AA \mathrm{Ti}$. The wafers were cleaved into $3 \mathrm{~cm} \times 3 \mathrm{~cm}$ squares and heated in a single zone tube furnace under a 5\% oxygen/95\% nitrogen flow of $100 \mathrm{sccm}$. The temperature range under investigation was from 200 to $600{ }^{\circ} \mathrm{C}$ for annealing times between $10 \mathrm{~min}$ and $30 \mathrm{~h}$. For each temperature, the furnace was first thermostatted to $\pm 1{ }^{\circ} \mathrm{C}$. The samples were placed into the loading zone of the furnace at ambient temperature and exposed to the $5 \%$ oxygen $/ 95 \%$ nitrogen flow. After a flushing time of $5 \mathrm{~min}$, the samples were slid into the hot zone of the furnace to bring the sample temperature quickly to the set point temperature. After completion of the desired annealing time, the samples were slid from the hot zone into the ambient-temperature loading zone where they cooled to ambient temperature under gas flow.

The film surface concentration measurements were performed using a Phi 5400 Perkin Elmer XPS with a base operating pressure of $1 \times 10^{-8}$ Torr or better. The system is equipped with a dual anode $\mathrm{Mg} / \mathrm{Al} \mathrm{x}$-ray source and a hemispherical electron energy analyzer. The spectra were acquired using $\operatorname{Mg} K \alpha$ radiation at $1253.6 \mathrm{eV}$. Survey scans were performed on samples in the range from 1000 to $0 \mathrm{eV}$ to verify the presence of $\mathrm{Pt}$ and $\mathrm{Ti}$, and to confirm that no unexpected elemental contamination was present. Analysis of the $\mathrm{Pt}(4 f), \mathrm{Ti}(2 p), \mathrm{O}(1 s)$, and $\mathrm{C}(1 s)$ energies were performed to examine binding energy shifts due to alloy formation or chemical reactions, such as oxidation. Due to the heterogeneous nature of the sample surface, only the relative amount of the elements on or near the surface could be calculated. The ratio of Pt and Ti was calculated from the unresolved peak areas of the Pt $4 f$ doublet and the $2 p$ doublet of Ti [Eq. (6)]. The atomic sensitivity factors (ASF) of 4.4 for the $\mathrm{Pt} 4 f$ and 1.2 for the Ti $2 p$ orbitals were used to ratio the $\operatorname{Pt}\left(f_{\mathrm{Pt}}\right)$ and $\operatorname{Ti}\left(f_{\mathrm{Ti}}\right)$ signal intensities from the doublet peaks of different electron orbitals. These atomic sensitivity factors are empirically derived values from data collected with Varian IEE and Perkin Elmer 550 spectrometers. ${ }^{23}$ The carbon $1 s$ peak was used as an internal calibrating standard for each sample surface to determine the electron charging effects.

$$
C_{\mathrm{Ti}}=\frac{\mathrm{ASF}_{\mathrm{Ti}} \int f_{\mathrm{Ti}}(\mathrm{eV})}{\mathrm{ASF}_{\mathrm{Ti}} \int f_{\mathrm{Ti}}(\mathrm{eV})+\mathrm{ASF}_{\mathrm{Pt}} \int f_{\mathrm{Pt}}(\mathrm{eV})} .
$$

Images of the film surface morphology were acquired with a Digital Instruments (DI) Nanoscope III atomic force microscope (AFM) with a $12 \mu \mathrm{m}$ scanning head (size D) under ambient conditions in intermittent contact (tapping mode). The AFM allows imaging of a large surface area of the film in combination with the necessary atomic resolution in the $z$ direction for the surface features of these films. Roughness measurements of the film surface were made with the DI data acquisition software (version 4.23).

\section{RESULTS}

XPS analysis of the five different thicknesses of Pt/Ti films before annealing showed no measurable titanium on or near the surface of the platinum layer. AFM results in Fig. 1 show that the surface morphology of the films changes substantially after annealing when the titanium reaches the surface. The images show the initial film surfaces (A), (B), and (C) and the change in surface morphology due to annealing at $500{ }^{\circ} \mathrm{C}$ for $30 \mathrm{~min}(\mathrm{E}, \mathrm{D}, \mathrm{F})$. The initial film surfaces are smooth and uniform in feature. The $35 \AA \mathrm{Pt} / 65 \AA \mathrm{Ti}(\mathrm{A})$ and the $65 \AA \mathrm{Pt} / 130 \AA \mathrm{Ti}$ (B) films are almost without surface features. With films of these thicknesses, there may be some contribution to the image of the thermally grown silicon dioxide morphology underneath the film. The $500 \AA \mathrm{Pt} / 500 \AA$ $\mathrm{Ti}$ (E) film after heating shows substantial changes in surface appearance $(\mathrm{F})$ due to Ti migration. The titanium diffusion causes an increase in roughness of the films that can be measured by AFM (Table I). While the thinnest, $35 \AA$ Pt/65 ̊ Ti film remains more or less unchanged within experimental error, the $65 \AA \mathrm{Pt} / 130 \AA \mathrm{Ti}$ film and the $500 \AA \mathrm{Pt} / 500 \AA \mathrm{Ti}$ film show substantial increases in surface roughness.

The diffusivity of Ti through the Pt film layers is determined using the idealized diffusion models by Holloway and McGuire $^{20}$ and Hwang and Balluffi ${ }^{21}$ for each of the five different film thicknesses. Arrhenius plots of the calculated grain boundary diffusion coefficients versus the inverse absolute temperature are constructed to determine the activation energy and the pre-exponential factor. The three sigma 

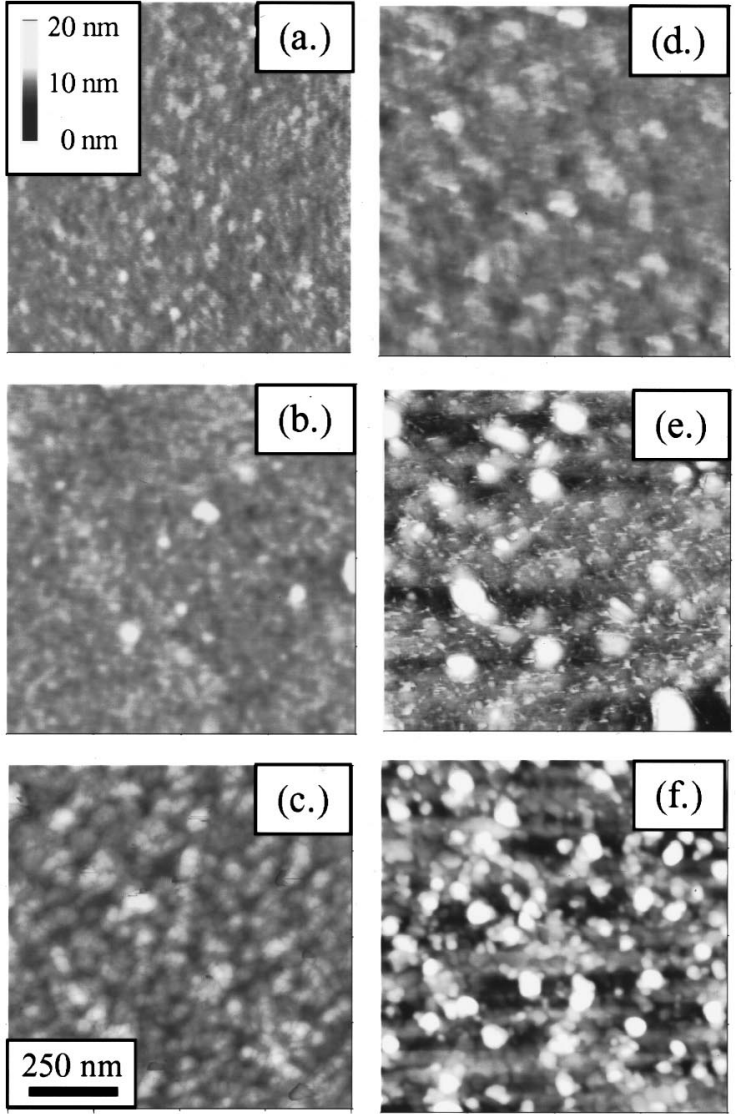

FIG. 1. AFM images of deposited: $35 \AA \mathrm{Pt} / 65 \AA$ Ti film (A), $65 \AA \mathrm{Pt} / 130 \AA$ Ti film (B), and $500 \AA \mathrm{Pt} / 500 \AA$ Ti film (C), compared with after annealing at $500{ }^{\circ} \mathrm{C}$ for 30 min: $35 \AA \mathrm{Pt} / 65 \AA$ Ti film (D), $65 \AA \mathrm{Pt} / 130 \AA \mathrm{T}$ Ti film (E), and $500 \AA \mathrm{Pt} / 500 \AA$ Ti film $(\mathrm{F})$.

uncertainty in the activation energy is determined from the best fit line in the slope. There is large uncertainty in the pre-exponential values due to the logarithmic dependence of the values.

As shown in Fig. 2, the results of the analysis with the Holloway and McGuire method ${ }^{20}$ and Hwang and Balluffi method $^{21}$ agree within the experimental uncertainty with the results of the diffusion experiments. The results of the calculated diffusion values for all five film thicknesses are summarized in Table II. The activation energies for titanium grain boundary diffusion in the 800 and $500 \AA$ films show very similar values averaging $118 \pm 15 \mathrm{~kJ} / \mathrm{mol}(1.22 \pm 0.16$ $\mathrm{eV})$. With the $200 \AA \mathrm{Pt} / 200 \AA \mathrm{Ti}$ film, a slightly lower average value of about $97 \pm 4 \mathrm{~kJ} / \mathrm{mol}(1.0 \pm 0.04 \mathrm{eV})$ is found.

However, this trend towards lower average activation energy values becomes more pronounced as the films get thinner. The diffusivity of the titanium through the $65 \AA$ $\mathrm{Pt} / 130 \AA$ Ai film is measurably faster compared to the thicker

TABLE I. Initial and final roughness values for Pt/Ti films.

\begin{tabular}{ccc}
\hline \hline Film & Initial roughness $(\AA)$ & Final roughness $(\AA)$ \\
\hline $35 \AA \mathrm{Pt} / 65 \AA \mathrm{Ti}$ & $4.5 \pm 0.7$ & $5.6 \pm 0.9$ \\
$65 \AA \mathrm{Pt} / 130 \AA \mathrm{Ti}$ & $4.2 \pm 1.1$ & $22.1 \pm 7.2$ \\
$500 \AA \mathrm{Pt} / 500 \AA \mathrm{Ti}$ & $21.3 \pm 1.6$ & $67.3 \pm 14.1$ \\
\hline \hline
\end{tabular}
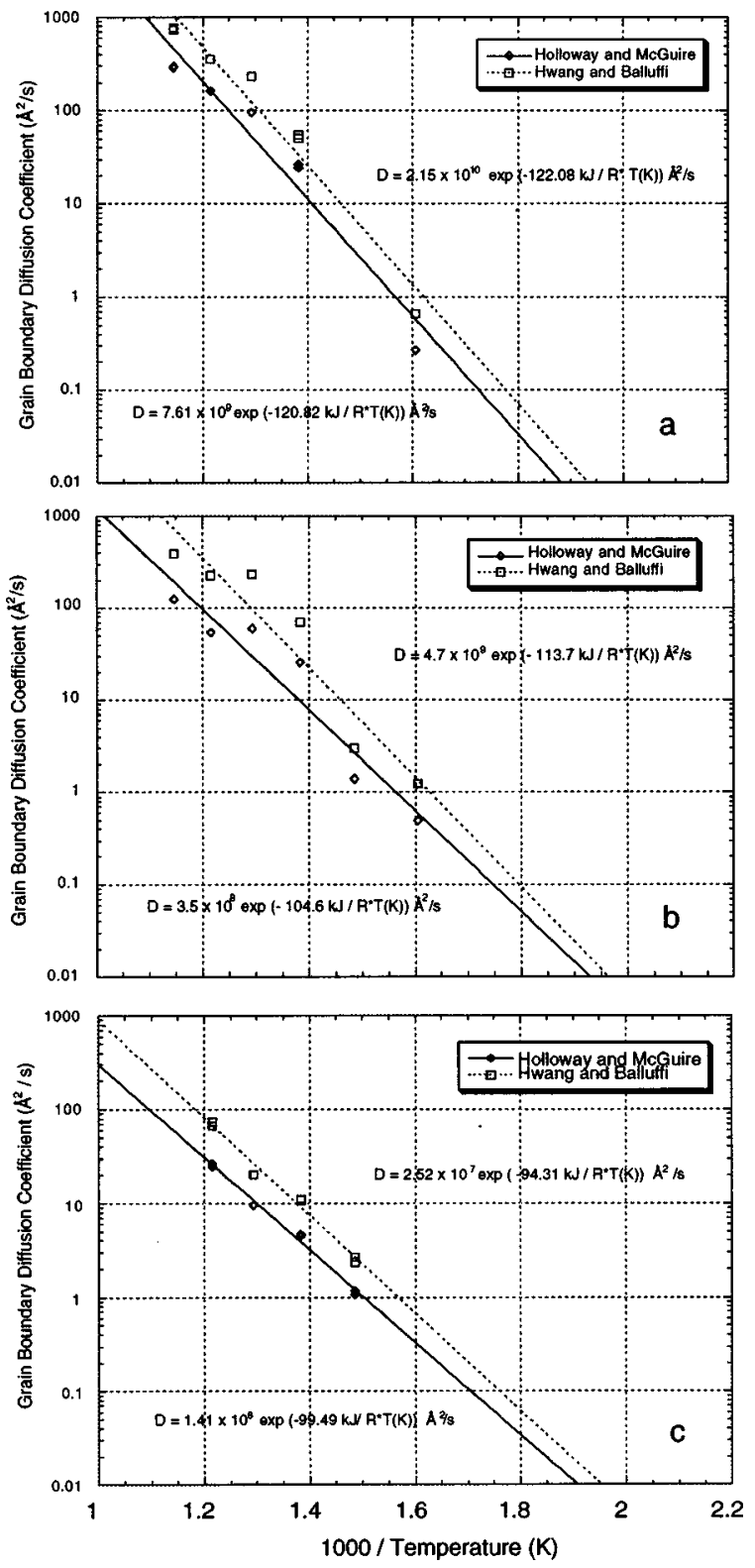

FIG. 2. The dependence of the grain boundary diffusion coefficient $\left(D_{b}\right)$ with temperature using the Holloway and McGuire and Hwang and Balluffi models: (a) $800 \AA \mathrm{Pt} / 800 \AA \mathrm{Ti}$ film, (b) $500 \AA \mathrm{Pt} / 500 \AA \mathrm{Ti}$ film, (c) $200 \AA$ $\mathrm{Pt} / 200 \AA$ A Ti film.

films. This can be seen by the decrease in the activation energy for diffusion in Fig. 3. The analysis from Holloway and McGuire method ${ }^{20}$ gives an activation energy of only $57.7 \pm 18.6 \mathrm{~kJ} / \mathrm{mol}(0.598 \pm 0.193 \mathrm{eV})$ and a diffusion coeffi-

TABLE II. Pre-exponential factors and activation energies for grain boundary diffusion.

\begin{tabular}{lllllc}
\hline \hline \multirow{2}{*}{$\begin{array}{c}\text { Film } \\
\text { thickness }\end{array}$} & \multicolumn{2}{c}{ Holloway and McGuire } & & \multicolumn{2}{c}{ Hwang and Balluffi } \\
\cline { 2 - 3 } \cline { 5 - 6 } & $D_{0}\left(\mathrm{~cm}^{2} / \mathrm{s}\right)$ & $Q_{b}(\mathrm{~kJ} / \mathrm{mol})$ & & $D_{0}\left(\mathrm{~cm}^{2} / \mathrm{s}\right)$ & $Q_{b}(\mathrm{~kJ} / \mathrm{mol})$ \\
\hline $800 \AA \mathrm{Pt}$ & $7.6 \times 10^{-6}$ & $121 \pm 10.4$ & & $2.2 \times 10^{-6}$ & $122 \pm 9.3$ \\
$500 \AA \mathrm{Pt}$ & $4.7 \times 10^{-6}$ & $114 \pm 16.9$ & & $3.5 \times 10^{-8}$ & $105 \pm 18.9$ \\
$200 \AA \mathrm{Pt}$ & $1.4 \times 10^{-8}$ & $99.5 \pm 3.9$ & & $2.5 \times 10^{-9}$ & $94.3 \pm 5.1$ \\
$65 \AA \mathrm{Pt}$ & $2.1 \times 10^{-11}$ & $57.7 \pm 18.6$ & & $1.2 \times 10^{-11}$ & $61.8 \pm 22.4$ \\
$35 \AA \mathrm{Pt}$ & $8.4 \times 10^{-15}$ & $19.8 \pm 4.2$ & & $3.7 \times 10^{-15}$ & $21.5 \pm 3.2$ \\
\hline \hline
\end{tabular}




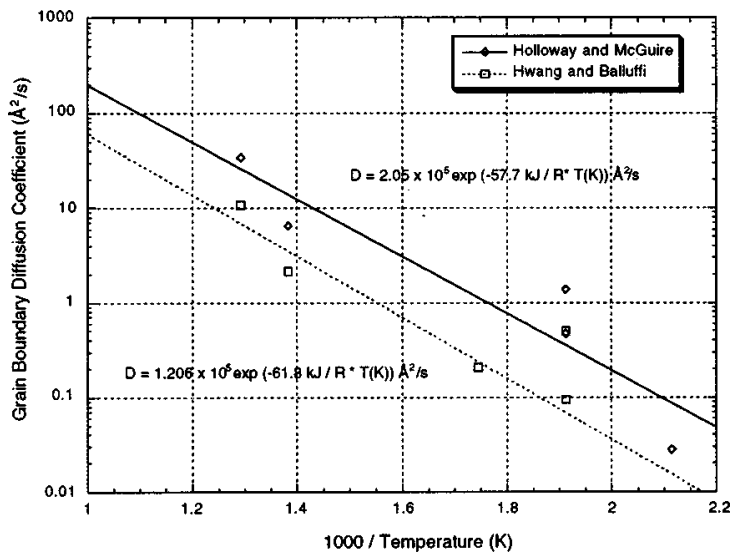

FIG. 3. The dependence of the rate of titanium diffusion with temperature in the $65 \AA \mathrm{Pt} / 130 \AA$ Ti film.

cient of $2.05 \times 10^{-11} \mathrm{~cm}^{2} / \mathrm{s}$. The analysis from Hwang and Balluffi ${ }^{21}$ agrees within the uncertainty limits. Using their method, the activation energy for titanium diffusion is 61.8 $\pm 22.4 \mathrm{~kJ} / \mathrm{mol}(0.641 \pm 0.0232 \mathrm{eV})$. The diffusion coefficient for this film thickness is $1.2 \times 10^{-11} \mathrm{~cm}^{2} / \mathrm{s}$.

Using the analysis from Holloway and McGuire, ${ }^{20}$ the activation energy for titanium diffusion through the $35 \AA$ $\mathrm{Pt} / 65 \AA \mathrm{Ti}$ film is calculated to be $21.5 \pm 4.3 \mathrm{~kJ} / \mathrm{mol}(0.223$ $\pm 0.045 \mathrm{eV}$ ) from the slope of the Arrhenius plot line in Fig. 4. The calculated diffusion coefficient is $37.1 \AA^{2} / \mathrm{s}$. Analysis of the data using the Hwang and Balluffi method, ${ }^{21}$ provides an activation energy of $19.8 \pm 3.2 \mathrm{~kJ} / \mathrm{mol}(0.205 \pm 0.033 \mathrm{eV})$ and a diffusion coefficient of $84.1 \AA^{2} / \mathrm{s}$. There is good agreement between the methods within the uncertainty of the values.

The comparison of XPS spectra in Fig. 5, from the $35 \AA$ $\mathrm{Pt} / 65 \AA$ Ti films after annealing for $10 \mathrm{~min}$, show an increase in the $\mathrm{TiO}_{2-x} 2 p$ peak intensity with annealing temperature. The doublet peak maximums of 458.0 and $463.2 \mathrm{eV}$ are lower than the standard positions for $\mathrm{TiO}_{2}$ intensities $(458.5$ and $464.4 \mathrm{eV}) .{ }^{24}$ At temperatures between 200 and $450{ }^{\circ} \mathrm{C}$, the results show that the titania is not in a fully oxidized state. This conclusion agrees with previously published work by Walton et al. for similar $35 \AA \mathrm{Pt} / 65 \AA \mathrm{Ti}$ films. ${ }^{7}$ At

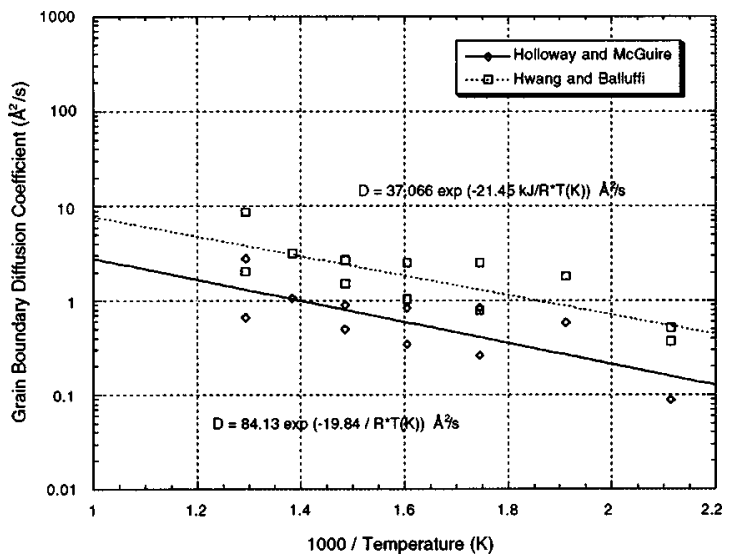

FIG. 4. The dependence of the rate of titanium diffusion with temperature in the $35 \AA \mathrm{Pt} / 65 \AA$ Ti film.

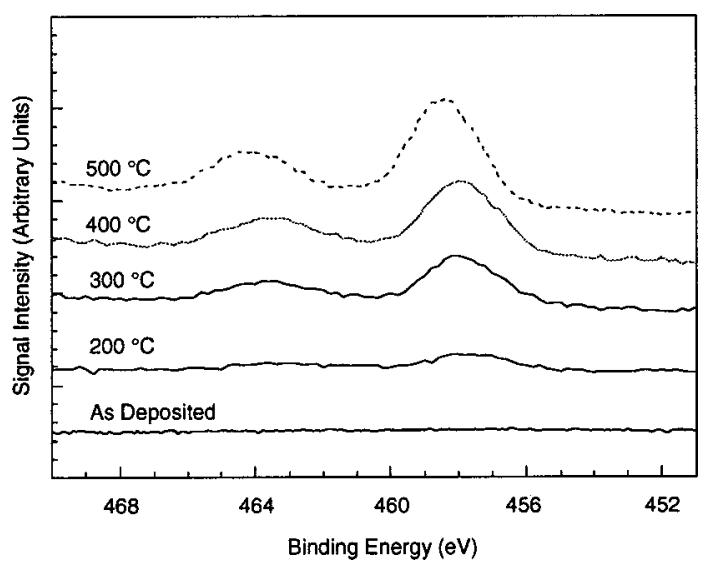

FIG. 5. The titanium diffusion to the surface of the $35 \AA \mathrm{Pt} / 65 \AA \mathrm{Ti}$ film after a 10 min anneal.

$500{ }^{\circ} \mathrm{C}$, the maximum peak intensities shift to 458.4 and $464.4 \mathrm{eV}$ due to the complete oxidation of the titanium to $\mathrm{TiO}_{2}$ at the higher temperature.

The corresponding Pt $4 f$ regions of the XPS spectra for the $35 \AA \mathrm{Pt} / 65 \AA \mathrm{Ti}$ films show the doublet maximums at 69.4 and $72.8 \mathrm{eV}$ in Fig. 6. These binding energy values are higher than reported values, but are similar to values reported for $\mathrm{Pt}$ on $\mathrm{TiO}_{2}$ layers. ${ }^{25,26}$ The $\mathrm{C} 1 s$ peak remains at $284.6 \mathrm{eV}$, ruling out significant charging effects on these $\mathrm{Pt}$ films. The shift in platinum binding energy can be attributed to the deposition procedure. After the titanium layer is deposited, the sample is exposed to ambient atmosphere before the platinum layer is deposited. This procedure allows oxygen at the interface. Analysis of the Pt peak positions after annealing at higher temperatures does not reveal any shifts in binding energy compared to the as-deposited film, indicating that the Pt layer is not involved in any reactions, such as $\mathrm{PtTi}_{3}$ or other alloy formation.

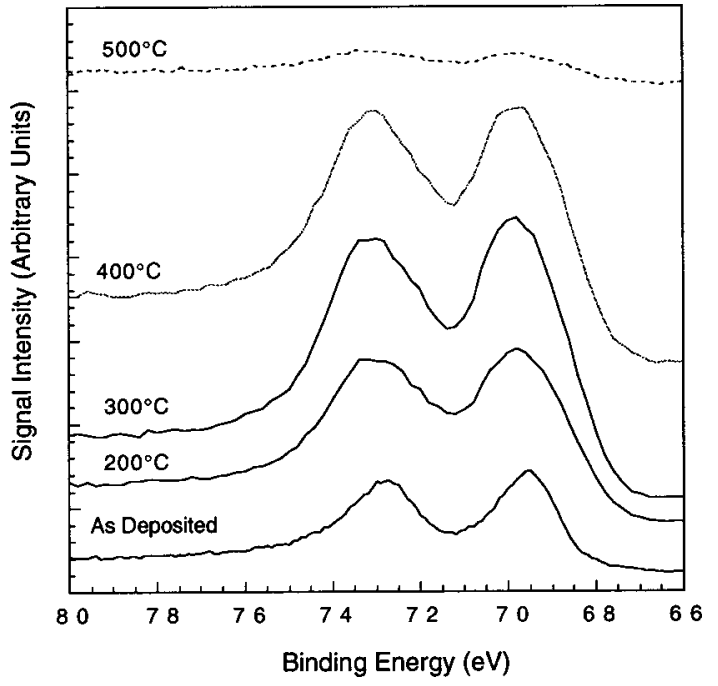

FIG. 6. A comparison of the Pt $4 f$ XPS spectra from the $35 \AA \mathrm{Pt} / 65 \AA \mathrm{Ti}$ films annealed at different temperatures for $10 \mathrm{~min}$. 


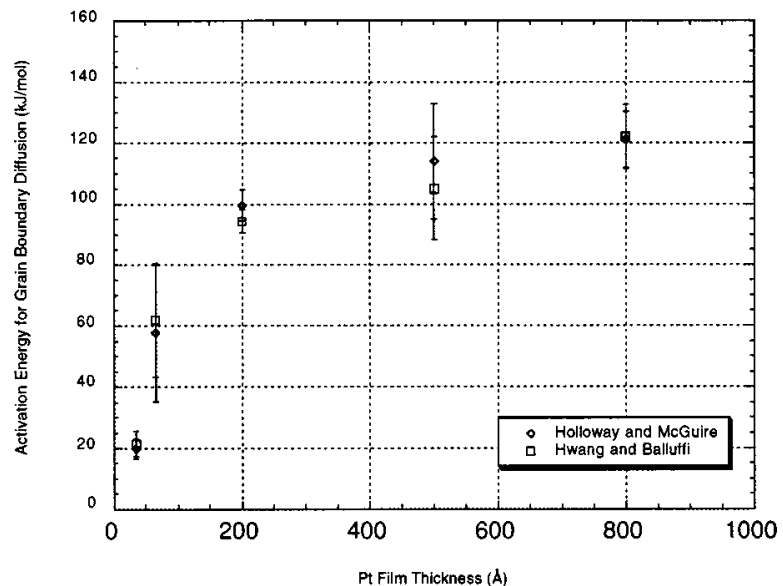

FIG. 7. The dependence of the titanium diffusion activation energy with the Pt film thickness.

\section{DISCUSSION}

After annealing, the change in film surface appearance can be clearly seen in the AFM images. Hillocks of $\mathrm{TiO}_{x}$ are present on the surface, as a result of titanium migration to the surface and oxidation. These changes in AFM images are similar to SEM observations in $100 \AA \mathrm{Pt} / 100 \AA \mathrm{Ti}^{6}$ and 800 $\AA \mathrm{Pt} / 700 \AA$ Ti films. ${ }^{3}$

The underlying assumptions for both the Holloway and McGuire $^{20}$ and Hwang and Balluffi ${ }^{21}$ models seem to hold for these temperature ranges with these materials. The results of both analysis methods show good agreement in the activation energy for each of the film thicknesses. Diffusion in the thin films is assumed to be a type $C$ mechanism, where $\mathrm{Ti}$ moves solely through the grain boundaries to the surface. There is a dependence of the activation energy on film thickness. In the thinnest films, defects and dislocations are likely to make significant contributions to the diffusion of Ti to the surface. The annealing temperatures were well below $0.6 \mathrm{~T}_{\text {melt }}$ and in the thinnest films the annealing times were very short $(10 \mathrm{~min})$ at higher temperatures $\left(600^{\circ} \mathrm{C}\right)$. The melting point of $\mathrm{Pt}$ is $2045 \mathrm{~K}$, and in this study the maximum temperature was $873 \mathrm{~K}\left(0.43 \mathrm{~T}_{\text {melt }}\right)$.

Figure 7 is a plot of the Pt film thickness versus the activation energy. Initially, the activation energy value is low $(21 \mathrm{~kJ} / \mathrm{mol})$ but increases to a nearly constant value as the film thickness increases. The activation energy reaches $118 \pm 15 \mathrm{~kJ} / \mathrm{mol}$ in the $500 \AA \mathrm{Pt} / 500 \AA \mathrm{Ti}$ and the $800 \AA$ $\mathrm{Pt} / 800 \AA$ Ti films. To the best of our knowledge, bulk diffusion values for $\mathrm{Pt} / \mathrm{Ti}$ are unavailable in published handbooks and other articles, ${ }^{1,13,15,27}$ but rapid Ti diffusion has been observed in other published works. ${ }^{6}$ Sreenivas et al. report $\mathrm{TiO}_{2}$ on the $\mathrm{Pt}$ surface after a $2 \mathrm{~min}$ anneal at $800^{\circ} \mathrm{C}$. The calculated activation energy agrees with the activation energies for grain boundary diffusion in similar metal bilayer systems as shown in Table III. In the $100 \AA \mathrm{Ti} / 100 \AA \mathrm{Ni}$ system, the activation energy for $\mathrm{Ni}$ grain boundary diffusion is $41.5 \mathrm{~kJ} / \mathrm{mol}(0.43 \mathrm{eV})$, which is similar to the activation energy of $\sim 60 \mathrm{~kJ} / \mathrm{mol}(0.62 \mathrm{eV})$ for the $200 \AA \mathrm{Pt} / 200 \AA \mathrm{Ti}$ film. In the $\mathrm{Au} / \mathrm{Rh}, \mathrm{Pt} / \mathrm{Au}$, and $\mathrm{Ti} / \mathrm{Al}$ systems, the activation energy for grain boundary diffusion is on the same order of
TABLE III. Grain boundary diffusion values for selected thin films.

\begin{tabular}{ccccc}
\hline \hline Element & Tracer & $D_{0}\left(\mathrm{~cm}^{2} / \mathrm{s}\right)$ & $Q_{b}(\mathrm{~kJ} / \mathrm{mol})$ & Reference \\
\hline $\mathrm{Ti}[100 \AA]$ & $\mathrm{Ni}[100 \AA]$ & $1.7 \times 10^{-20}$ & 41.5 & 28 \\
$\mathrm{Au}[700 \AA]$ & $\mathrm{Rh}[700 \AA]$ & $4.2 \times 10^{-11}$ & 90.7 & 2 \\
$\mathrm{Pt}[<800 \AA]$ & $\mathrm{Au}[<800 \AA]$ & $1.2 \times 10^{-3}$ & 159 & 18 \\
$\mathrm{Al}[4000 \AA]$ & $\mathrm{Ti}[2000 \AA]$ & $1.27 \times 10^{1}$ & 195 & 29 \\
\hline \hline
\end{tabular}

magnitude as the $\mathrm{Pt} / \mathrm{Ti}$ values for similar thicknesses. In the Ti/Al bilayer systems, the diffusion pre-exponential coefficient is strongly dependent on deposition conditions of the film because those conditions influence grain size and defect density, but the activation energy remains constant. ${ }^{29}$

The reaction of platinum and titanium at the interface to form an alloy would affect the diffusion of titanium to the surface. Alloying reactions of the Pt and Ti have been studied by XRD at the interface in other works. ${ }^{30,31}$ At $500{ }^{\circ} \mathrm{C}$, the most common alloy reported is $\mathrm{Pt}_{3} \mathrm{Ti}$ but it is difficult to measure conclusively because $\mathrm{Pt}_{3} \mathrm{Ti}(3.904 \AA$ ) has nearly the same lattice constant as Pt (3.9231 $\AA$ ). In our case, there was no shift in the XPS Pt peak intensity position, even in the thinnest bilayer system $(35 \AA \mathrm{Pt} / 65 \AA \mathrm{Ti})$, indicating that the materials from these layers had not formed an alloy at $500^{\circ} \mathrm{C}$. The formation of $\mathrm{Pt}_{3} \mathrm{Ti}$ is probably inhibited by the exposure to oxygen in between metal deposition steps that suppresses the nucleation sites for alloying. A similar results is observed in the $\mathrm{Al} / \mathrm{Ti}$ system, where oxygen contamination at the interface suppressed the formation of $\mathrm{TiAl}_{3} .{ }^{29}$

\section{CONCLUSION}

At temperatures between 200 and $500{ }^{\circ} \mathrm{C}$, the diffusion kinetics for the $\mathrm{Pt} / \mathrm{Ti}$ system demonstrate that in the thin films ( $>200 \AA$ ) the diffusion is a function of film thickness. The activation energy required for diffusion is significantly lower than for the thicker film samples. As the film thickness increases to above $200 \AA$, the diffusion kinetics achieve constant values in the range of $200-600^{\circ} \mathrm{C}$. The pre-exponential factor is $2.2 \times 10^{-6} \mathrm{~cm}^{2} / \mathrm{s}$ and the activation energy is $118 \pm 15 \mathrm{~kJ} / \mathrm{mol}(1.22 \pm 0.16 \mathrm{eV})$. This value is on the same order of magnitude as the quantitative grain-boundary diffusion results for other similar metal bilayer systems.

There is no observable shift in XPS Pt peak position indicating the absence of alloy formation. The presence of oxygen at the interface of the metals is believed to suppress the nucleation sites for $\mathrm{Pt}_{3} \mathrm{Ti}$ formation. This quantitative diffusion information can be valuable for the determination of the Pt/Ti surface concentration for chemical sensing films, or understanding the operational characteristics of interconnects.

\section{ACKNOWLEDGMENTS}

The authors would like to thank Professor Kensall D. Wise and Christine Tom for the film depositions, and Corinna Wauchope for assistance with the XPS.

${ }^{1}$ T. C. Tisone and J. Drobek, J. Vac. Sci. Technol. 9, 271 (1971).

${ }^{2}$ W. J. Debonte, J. M. Paote, C. M. Melliar-Smith, and R. A. Levesque, J. Appl. Phys. 46, 4284 (1975). 
${ }^{3}$ K. H. Park, C. Y. Kim, Y. W. Jeong, H. J. Kwon, and K. Y. Kim, J. Mater. Res. 10, 1790 (1995).

${ }^{4}$ O. Olowolafe, R. E. Jones, Jr., A. C. Campbell, R. I. Hedge, C. J. Mogab, and R. B. Gregory, J. Appl. Phys. 73, 1764 (1993).

${ }^{5}$ R. E. Jones, Jr., P. D. Maniar, J. L. Dupuie, J. Kim, R. Moazzami, J. Witowske, M. L. Kottke, N. C. Saha, and R. B. Gregory, in Ferroelectric Thin Films IV, edited by B. A. Tuttle, S. B. Desu, R. Ramesh, and T. Shiosaki (Materials Research Society, Pittsburgh, PA 1995), pp. 223-228.

${ }^{6}$ K. Sreenivas, I. Reaney, T. Maeder, N. Setter, C. Jagadish, and R. G. Elliman, J. Appl. Phys. 75, 232 (1994).

${ }^{7}$ R. M. Walton, D. J. Dwyer, J. W. Schwank, and J. L. Gland, Appl. Surf. Sci. 125, 187 (1998).

${ }^{8}$ R. M. Walton, H. Liu, J. L. Gland, and J. W. Schwank, Sens. Actuators B 41, 143 (1997).

${ }^{9}$ S. V. Patel, M. DiBattista, J. L. Gland, and J. W. Schwank, Sens. Actuators B 37, 27 (1996).

${ }^{10}$ J. Sheng, N. Yoshida, J. Karasawa, and T. Fukami, Sens. Actuators B 41, 131 (1997).

${ }^{11}$ J. Herrmann and P. Pichat, J. Catal. 78, 425 (1982).

${ }^{12}$ C. Pliangos, I. V. Yentekakis, S. Ladas, and C. G. Vayenas, J. Catal. 159, 189 (1996).

${ }^{13}$ P. Shewmon, Diffusion in Solids (The Minerals, Metals, and Materials Society, Warrendale, PA, 1989).

${ }^{14}$ Smithells Metals Reference Book, 7th ed., edited by E. A. Brandes and G. B. Brook (Butterworth-Heinemann, Oxford, 1992).

${ }^{15}$ Diffusion in Solid Metals and Alloys, Landolf-Burnstein New Series, edited by H. Mehrer (Springer, Berlin, 1990), Vol. III/26.

${ }^{16}$ I. Kaur, Y. Mishin, and W. Gust, Fundamentals of Grain and Interphase Boundary Diffusion, 3rd ed. (Wiley, West Sussex, 1995).

${ }^{17}$ K.-N. Tu, J. W. Mayer, and L. C. Feldman, Electronic Thin Film Science (Macmillan, New York, 1992).
${ }^{18}$ W. B. Nowak and R. N. Dyer, J. Vac. Sci. Technol. 9, 279 (1971).

${ }^{19}$ L. G. Harrison, Trans. Faraday Soc. 57, 1191 (1961).

${ }^{20}$ P. H. Holloway and G. E. McGuire, J. Electrochem. Soc. 125, 2070 (1978).

${ }^{21}$ J. C. M. Hwang and R. W. Balluffi, J. Appl. Phys. 50, 1339 (1979).

${ }^{22}$ H. S. Carslaw and J. C. Jaeger, Conduction of Heat in Solids, 2nd ed. (Oxford Clarendon, London, 1958).

${ }^{23}$ D. Briggs and M. P. Seah, Practical Surface Analysis by Auger and X-ray Photoelectron Spectroscopy (Wiley, New York, 1983).

${ }^{24}$ Handbook of X-ray Photoelectron Spectroscopy, edited by C. D. Wagner, W. M. Riggs, L. E. Davis, J. F. Moulder, and C. F. Muilenberg (Physical Electronics Industries, Eden, Minnesota, 1979).

${ }^{25}$ Y.-M. Sun, D. N. Belton, and J. M. White, J. Phys. Chem. 90, 5178 (1986).

${ }^{26}$ T. Sasaki, R. Rozbicki, Y. Matsumoto, N. Koshizaki, S. Terauchi, and H. Umehara, in Nanophase and Nanocomposite Materials II, edited by S. Komarneni, J. C. Parker, and H. J. Wollenberger (Materials Research Society, Pittsburgh, PA 1997), Vol. 457, pp. 425-430.

${ }^{27}$ J. Askill, Tracer Diffusion Data for Metals, Alloys, and Simple Oxides (IFI/Plenum, New York, 1963).

${ }^{28}$ M. Maaza, C. Sella, J. P. Ambroise, M. Kaabouchi, M. Miloche, F. Wehling, and M. Groos, J. Appl. Crystallogr. 26, 334 (1993).

${ }^{29}$ X. A. Zhao, F. C. T. So, and M. A. Nicolet, J. Appl. Phys. 63, 2800 (1988).

${ }^{30}$ F. Varniere, B. E. Kim, B. Agius, R. Bisaro, J. Olivier, G. Chevrier, H. Achard, H. Mace, and L. Peccoud, in Ferroelectric Thin Films IV, edited by B. A. Tuttle, S. B. Desu, R. Ramesh, and T. Shiosaki (Materials Research Society, Pittsburgh, PA 1995), Vol. 361, pp. 235-240.

${ }^{31}$ A. Ehrlich, U. Weiß, W. Hoyer, and T. Geßner, Thin Solid Films 300, 122 (1997). 